\title{
Impact damage analysis for glass reinforced epoxy laminated plates using single stage gas gun
}

\begin{abstract}
The overall purpose of the research is to investigate the effect of thickness on fiberglass reinforced epoxy laminates. In this study, simplified coupon specimens made from Epoxy/Cglass $(200 \mathrm{~g} / \mathrm{m} 2)$ and Epoxy/C-glass $(600 \mathrm{~g} / \mathrm{m} 2)$ with different thicknesses were used. To perform the high velocity impact tests $(250 \mathrm{~m} / \mathrm{s})$, an instrumented single stage gas gun was used. The impacted specimens were examined to determine the extent of damages induced around the impacted point. For the projectiles velocity of $250 \mathrm{~m} / \mathrm{s}$, it was found that Epoxy/Cglass $200 \mathrm{~g} / \mathrm{m} 2$ was able to absorb $21.5 \mathrm{~J}$ of energy at the thickness of $12 \mathrm{~mm}$, while Epoxy/C-glass $600 \mathrm{~g} / \mathrm{m} 2$ was able to absorb $96.1 \mathrm{~J}$ of energy at $10 \mathrm{~mm}$ thickness. Both the fibreglasses compute damage in terms of slight matrix breakage and cracking. A general trend was observed on the overall ballistic test results, which indicated that, as the plate thickness continue to increase, the damage at the lower skin decreases and could not be seen.
\end{abstract}

Keyword: Fibre breakage; Fibre cracking; Fibre glass reinforced polymer (FGRP); Matrix breakage; Matrix cracking; Single stage gas gun 